\title{
Modeling the impact of a potential shale gas industry in Germany and the United Kingdom on ozone with WRF-Chem
}

\author{
Lindsey B. Weger ${ }^{1,2 *}$, Aurelia Lupascu ${ }^{1}$, Lorenzo Cremonese ${ }^{1}$ and Tim Butler ${ }^{1,3}$ \\ ${ }^{1}$ Institute for Advanced Sustainability Studies (IASS), Potsdam, DE \\ ${ }^{2}$ Institut für Geowissenschaften, Universität Potsdam, Potsdam, DE \\ ${ }^{3}$ Institut für Meteorologie, Freie Universität Berlin, Berlin, DE \\ *lindsey.weger@iass-potsdam.de
}

\section{Supplemental material}

Table S1. Namelist used in simulations with WRF-Chem

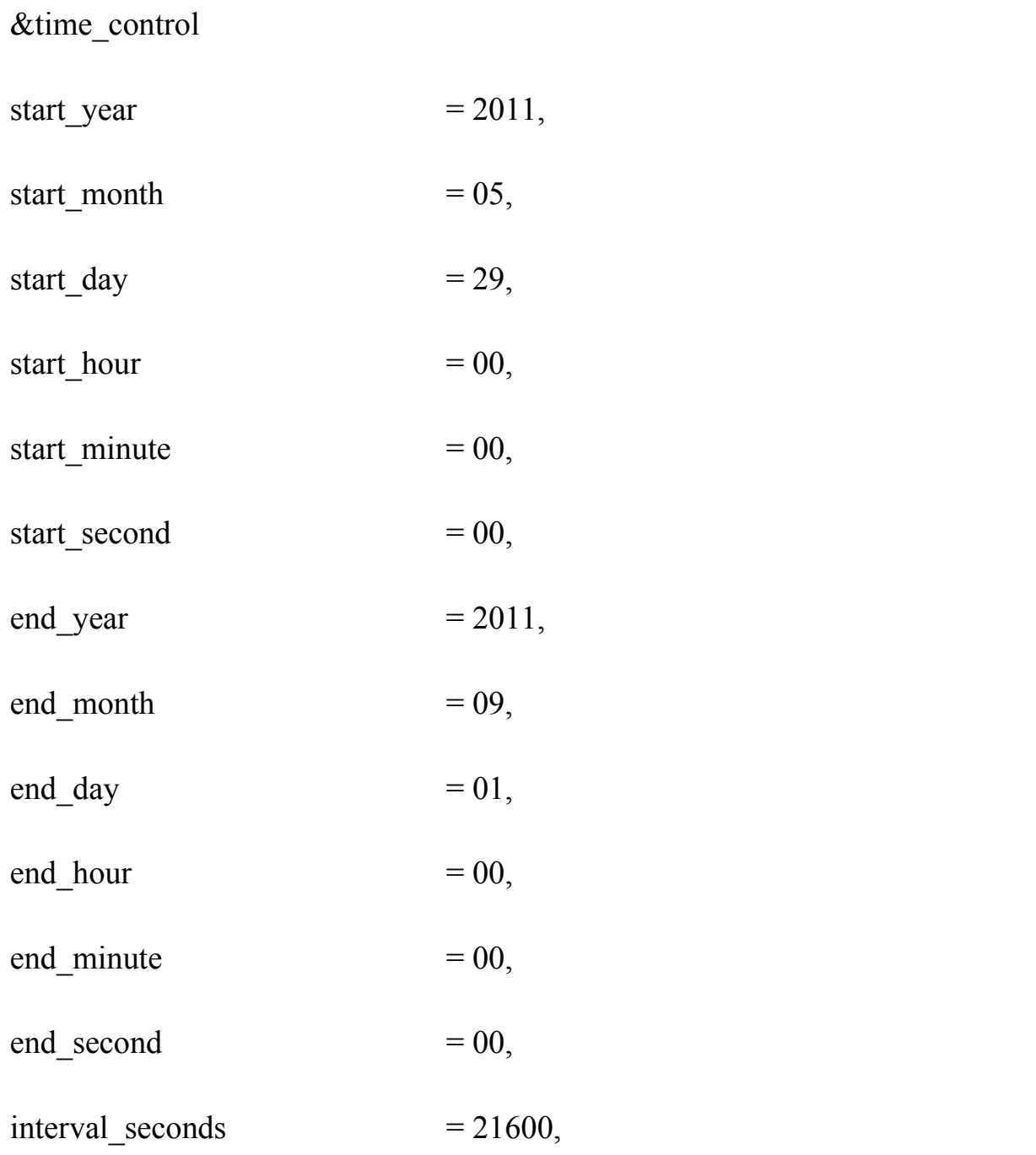




$$
\begin{aligned}
& \text { input_from_file } \\
& =\text {.true., } \\
& \text { history_interval }=60 \text {, } \\
& \text { frames_per_outfile } \quad=1 \text {, } \\
& \text { restart }=\text {.false., } \\
& \text { restart_interval }=1440, \\
& \text { io_form_history =2, } \\
& \text { io_form_input } \quad=2 \text {, } \\
& \text { io_form_boundary } \quad=2 \text {, } \\
& \text { auxinput4_inname = 'wrflowinp_d }<\text { domain }>\text { ', } \\
& \text { auxinput4_interval =360, } \\
& \text { io_form_auxinput4 =2, } \\
& \text { output_diagnostics } \quad=1 \text {, } \\
& \text { auxhist3_outname = wrfxtrm_d }<\text { domain }>\text { _ }<\text { date }>\text {, } \\
& \text { auxhist3_interval = 1440, } \\
& \text { frames_per_auxhist3 = } 1 \text {, } \\
& \text { io_form_auxhist3 = } 2 \text {, } \\
& \text { debug_level }=0 \text {, } \\
& \text { auxinput5_inname = 'wrfchemi_d }<\text { domain }>\text { _ }<\text { date }>\text { ', } \\
& \text { auxinput6_inname = 'wrfbiochemi_d }<\text { domain }>\text { ', } \\
& \text { frames_per_auxinput5 } \quad=1 \text {, } \\
& \text { auxinput5_interval_h } \quad=1 \text {, } \\
& \text { io_form_auxinput5 =2, }
\end{aligned}
$$




\begin{tabular}{|c|c|c|c|c|c|}
\hline io_form_auxinput6 & $=2$ & & & & \\
\hline / & & & & & \\
\hline \&domains & & & & & \\
\hline time_step & $=60$ & & & & \\
\hline time_step_fract_num & $=0$ & & & & \\
\hline time_step_fract_den & $=1$, & & & & \\
\hline max_dom & $=1$, & & & & \\
\hline e_we & $=150$ & & & & \\
\hline e_sn & $=150$ & & & & \\
\hline e_vert & $=35$ & & & & \\
\hline p_top_requested & $=5000$ & & & & \\
\hline num_metgrid_levels & $=38$, & & & & \\
\hline eta_levels & $=$ & 1.0, & 0.993 & 0.983, & 0.97 , \\
\hline 0.954, & 0.934 & 0.909 & 0.88 & 0.845 & \\
\hline 0.807 & 0.765 & 0.719 & 0.672 & 0.622 & \\
\hline 0.571, & 0.52 & 0.468 & 0.42 & 0.376 & \\
\hline 0.335 & 0.298 & 0.263 & 0.231 & 0.202 & \\
\hline 0.175 & 0.15 & 0.127 & 0.106 & 0.088 & \\
\hline 0.07, & 0.055 & 0.04, & 0.026 & 0.013 & \\
\hline 0.0 & & & & & \\
\hline num_metgrid_soil_levels & $=4$ & & & & \\
\hline $\mathrm{dx}$ & $=15000$ & & & & \\
\hline
\end{tabular}




\begin{tabular}{|c|c|}
\hline dy & $=15000$, \\
\hline grid_id & $=1$ \\
\hline parent_id & $=1$ \\
\hline i_parent_start & $=1$ \\
\hline j_parent_start & $=1$, \\
\hline parent_grid_ratio & $=1$ \\
\hline parent_time_step_ratio & $=1$ \\
\hline feedback & $=0$ \\
\hline smooth_option & $=0$ \\
\hline / & \\
\hline \&physics & \\
\hline mp_physics & $=2$ \\
\hline ra_lw_physics & $=4$ \\
\hline ra_sw_physics & $=2$, \\
\hline radt & $=15$ \\
\hline sf_sfclay_physics & $=1$ \\
\hline sf_surface_physics & $=2$ \\
\hline bl_pbl_physics & $=1$ \\
\hline bldt & $=0$ \\
\hline cu_physics & $=5$ \\
\hline cu_rad_feedback & $=$.false. \\
\hline cudt & $=0$ \\
\hline
\end{tabular}




\begin{tabular}{|c|c|}
\hline isfflx & $=1$ \\
\hline ifsnow & $=1$ \\
\hline icloud & $=1$ \\
\hline surface_input_source & $=1$ \\
\hline num_soil_layers & $=4$ \\
\hline mp_zero_out & $=2$ \\
\hline mp_zero_out_thresh & $=1 . \mathrm{e}-12$, \\
\hline sf_urban_physics & $=1$, \\
\hline maxiens & $=1$ \\
\hline maxens & $=3$ \\
\hline maxens2 & $=3$ \\
\hline maxens 3 & $=16$ \\
\hline ensdim & $=144$ \\
\hline sst_update & $=1$ \\
\hline usemonalb & $=$.true. \\
\hline progn & $=1$ \\
\hline cu_diag & $=1$ \\
\hline num_land_cat & $=28$ \\
\hline \multicolumn{2}{|l|}{ / } \\
\hline \multicolumn{2}{|l|}{ \&fdda } \\
\hline grid_fdda & $=1$, \\
\hline
\end{tabular}




\begin{tabular}{|c|c|}
\hline gfdda_inname & $=$ wrffdda_d $<$ domain $>$, \\
\hline gfdda_interval_m & $=360$ \\
\hline gfdda_end_h & $=79200$ \\
\hline io_form_gfdda & $=2$ \\
\hline if_no_pbl_nudging_uv & $=1$ \\
\hline if_no_pbl_nudging_t & $=0$ \\
\hline if_zfac_uv & $=0$ \\
\hline k_zfac_uv & $=8$ \\
\hline if_zfac_t & $=0$ \\
\hline k_zfac_t & $=8$ \\
\hline guv & $=0.0003$ \\
\hline gt & $=0.0003$ \\
\hline if_ramping & $=1$, \\
\hline dtramp_min & $=60$ \\
\hline / & \\
\hline \&dynamics & \\
\hline rk_ord & $=3$ \\
\hline w_damping & $=1$, \\
\hline diff_opt & $=1$, \\
\hline km_opt & $=4$ \\
\hline diff_6th_opt & $=0$ \\
\hline diff_6th_factor & $=0.12$ \\
\hline
\end{tabular}




\begin{tabular}{|c|c|}
\hline base_temp & $=290$. \\
\hline damp_opt & $=0$ \\
\hline zdamp & $=5000$. \\
\hline dampcoef & $=0.01$, \\
\hline khdif & $=0$ \\
\hline kvdif & $=0$ \\
\hline non_hydrostatic & $=$.true., \\
\hline moist_adv_opt & $=2$ \\
\hline scalar_adv_opt & $=2$ \\
\hline chem_adv_opt & $=2$ \\
\hline tke_adv_opt & $=2$ \\
\hline time_step_sound & $=4$ \\
\hline h_mom_adv_order & $=5$ \\
\hline v_mom_adv_order & $=3$ \\
\hline h_sca_adv_order & $=5$ \\
\hline v_sca_adv_order & $=3$ \\
\hline / & \\
\hline \&bdy_control & \\
\hline spec_bdy_width & $=5$ \\
\hline spec_zone & $=1$ \\
\hline relax_zone & $=4$ \\
\hline specified & $=$.true., \\
\hline
\end{tabular}




\begin{tabular}{|c|c|}
\hline nested & $=$.false \\
\hline \multicolumn{2}{|l|}{ / } \\
\hline \&grib2 & \\
\hline / & \\
\hline \&namelist_quilt & \\
\hline nio_tasks_per_group & $=0$ \\
\hline nio_groups & $=1$ \\
\hline / & \\
\hline \&chem & \\
\hline kemit & $=1$, \\
\hline ne_area & $=100$, \\
\hline chem_opt & $=111$, \\
\hline bioemdt & $=1$. \\
\hline photdt & $=15$ \\
\hline chemdt & $=10$ \\
\hline io_style_emissions & $=2$ \\
\hline emiss_inpt_opt & $=1$ \\
\hline emiss_opt & $=7$ \\
\hline chem_in_opt & $=1$ \\
\hline phot_opt & $=3$ \\
\hline gas_drydep_opt & $=1$ \\
\hline
\end{tabular}




\begin{tabular}{|c|c|}
\hline aer_drydep_opt & $=0$ \\
\hline bio_emiss_opt & $=3$, \\
\hline gas_bc_opt & $=1$, \\
\hline gas_ic_opt & $=1$, \\
\hline gaschem_onoff & $=1$, \\
\hline aerchem_onoff & $=0$ \\
\hline wetscav_onoff & $=0$, \\
\hline cldchem_onoff & $=0$ \\
\hline vertmix_onoff & $=1$, \\
\hline chem_conv_tr & $=1$, \\
\hline seas_opt & $=0$, \\
\hline dust_opt & $=0$, \\
\hline biomass_burn_opt & $=0$, \\
\hline plumerisefire_frq & $=30$ \\
\hline have_bcs_chem & $=$.true., \\
\hline aer_ra_feedback & $=0$ \\
\hline opt_pars_out & $=0$ \\
\hline diagnostic_chem & $=0$ \\
\hline chemdiag & $=1$, \\
\hline
\end{tabular}

\section{Text S1. conNO $\mathrm{O}_{\mathrm{x}}$ scenario development}

In order to calculate the conNO ${ }_{\mathrm{x}}$ scenario emission flux for emissions pre-processing, first the area over which to concentrate the $\mathrm{NO}_{\mathrm{x}}$ emissions from drilling and fracking activities was calculated. Afterwards the $\mathrm{NO}_{\mathrm{x}}$ emissions for drilling and fracking activities from the REm-U P25 scenario from Cremonese et al. 
(2019), which make up $24 \%$ of total shale gas $\mathrm{NO}_{\mathrm{x}}$ emissions for Germany and $18 \%$ for the UK, were divided by space and time values to get the emissions flux in units of $\mathrm{kg} \mathrm{m}^{-2} \mathrm{~s}^{-1}$. These calculations are described here.

\section{Concentrated $\mathrm{NO}_{x}$ area}

Displayed below are calculation steps (1-4) to convert number of wells pads (WP) in Germany (DE) and in the United Kingdom (UK) from concentrated $\mathrm{NO}_{\mathrm{x}}$ activities to total area of concentrated $\mathrm{NO}_{\mathrm{x}}$ emissions for the conNO $\mathrm{N}_{\mathrm{x}}$ scenario, adjusted to fit the pre-processing grid to which emissions are added. Note that, according to Cremonese et al. (2019)'s REm-U P25 scenario which are used as the basis for all simulations in this work, 166 and 206 wells are both drilled and fracked annually in DE and the UK, respectively. These values were averaged to 42 and 52 wells that are drilled and fracked over the JJA period respective to $\mathrm{DE}$ and the $\mathrm{UK}$. In the $\operatorname{conNO}_{\mathrm{x}}$ scenario one drilling and one fracking activity are applied per pad, so that a uniform emissions flux can be applied to the entire Concentrated $\mathrm{NO}_{\mathrm{x}}$ area to reduce complexity (as opposed to say, half the concentrated $\mathrm{NO}_{\mathrm{x}}$ area containing drilling activities only with one emissions flux and the other area containing fracking activities only with a different emissions flux). With one fracking and one drilling activity per pad, a total of 42 and 52 WPs are utilized in DE and the UK, respectively.

\section{Calculation steps - Germany}

$$
\begin{aligned}
& 42 \text { pads }_{D E} \times 25 \mathrm{~km}_{W P \text { area }}^{2}=1050 \mathrm{~km}^{2} \text { total area } \\
& 1050 \mathrm{~km}_{W P, D E}^{2} / 49 \mathrm{~km}_{P P \text { area }}^{2}=21.43 \approx 20 \text { grid cells }_{P P, D E} \\
& 20 \mathrm{cell}_{P P, D E} \times 49 \mathrm{~km}_{P P \text { area }}^{2}=980 \mathrm{~km}^{2} \text { total area }_{P P, D E} \\
& 980 \mathrm{~km}^{2} \text { total area } \\
& P P, D E
\end{aligned}
$$

\section{Calculation steps - United Kingdom}

$$
\begin{aligned}
& 52 \text { pads }_{U K} \times 25 \mathrm{~km}_{W P \text { area }}^{2}=1300 \mathrm{~km}^{2} \text { total area } \\
& 1300 \mathrm{~km}_{W P, U K}^{2} / 49 \mathrm{~km}_{P P \text { area }}^{2}=26.53 \approx 25 \text { grid cells }_{P P, U K} \\
& 25 \mathrm{cell}_{P P, U K} \times 49 \mathrm{~km}_{P P \text { area }}^{2}=1225 \mathrm{~km}^{2} \text { total area } \\
& 1225 \mathrm{~km}^{2} \text { total area } \\
&
\end{aligned}
$$


Here we walk through the steps to calculate the concentrated $\mathrm{NO}_{\mathrm{x}}$ area, for each country. In calculation step 1 the number of WPs is multiplied by the WP area used in Cremonese et al. (2019) $\left(5 \mathrm{kmx} 5 \mathrm{~km}=25 \mathrm{~km}^{2}\right)$ to calculate total WP area for concentrated $\mathrm{NO}_{\mathrm{x}}$ emissions. In step 2, the WP area from step 1 is divided by the pre-processing (written as 'PP' in subscript) grid cell size $\left(7 \mathrm{kmx} 7 \mathrm{~km}=49 \mathrm{~km}^{2}\right.$, Kuenen et al. 2014) to adjust to the pre-processing grid, and subsequently rounded to produce a simple quadrilateral area. In step 3 the total concentrated $\mathrm{NO}_{\mathrm{x}}$ area adjusted to the pre-processing grid is calculated. Finally in step 4 the percentage of shale gas (written as ' $\mathrm{SG}$ ' in subscript) basin area consisting of concentrated $\mathrm{NO}_{\mathrm{x}}$ emissions is calculated, based on the size of the shale gas basins of these two countries. Note that the shale gas basin area is based on the raster grid used in our simulations.

\section{Concentrated $N O_{x}$ time}

According to Cremonese et al. (2019)'s REm-U P25 scenario, the time required to drill one well is $392 \mathrm{~h}$, or approximately 16.33 days. On the other hand, the time required to frack one stage is $2.5 \mathrm{~h}$, where there are a total of 41.7 stages per well. Because only one stage can be drilled at a time per well, this amounts to a total of 104.17 hours, or rather 4.34 days. In order to reduce complexity and have one emissions flux, all concentrated $\mathrm{NO}_{\mathrm{x}}$ emissions are averaged over one period of time, based on the time required to carry out the longer activity, i.e., drilling. Since it is necessary to apply daily values in emissions pre-processing, this period of time is rounded up to 17 days.

\section{Placement of Concentrated $\mathrm{NO}_{x}$ emissions based on sensitivity studies}

In the sensitivity study to select the location for the concentrated $\mathrm{NO}_{\mathrm{x}}$ emissions, the following steps were performed, for both Germany and the United Kingdom:

1. Shale gas basin mask netCDF file was converted from the emissions pre-processing grid to a mask adapted to the output grid, to analyze WRF-Chem output data in the shale gas regions only.

2. Areas classified as 'urban or built up land' in the USGS dataset were removed from the mask. This was done so as not to include areas which would be unrealistic for potential locations to add concentrated drilling and fracking activities.

3. The $\mathrm{j}, \mathrm{k}$, lat, lon, and MDA $8_{\text {Diff,max }}$ (scenario minus base) values were recorded per grid cell for each grid cell of the mask, and for each day of the simulation period. MDA8 $8_{\text {Diff,max }}$ is described in Equation $\mathbf{S 1}$ below.

4. This data was obtained for two scenarios: SG1-wet gas, and SG1-wet gas without added shale gas $\mathrm{NO}_{\mathrm{x}}$ emissions. Note that both scenarios contain added shale gas VOC emissions.

5. There are several shale gas basins for Germany, and so this data was filtered by removing coordinates and their corresponding values for German shale gas basins which were not large 
enough to accommodate the concentrated $\mathrm{NO}_{\mathrm{x}}$ area, i.e, Unterkarbon basins located in the Baltic Sea (near Rügen) and by the Ruhr Valley (see Cremonese et al. 2019) for depiction of basins and corresponding basin names). This was not performed for the UK, since it contains one large, continuous basin, i.e., the Bowland.

6. MDA8 $8_{\text {Diff,max }}$ values: SG1-wet gas (no $\mathrm{NO}_{\mathrm{x}}$ ) values were subtracted from SG1-wet gas (aptly referred to here as MDA $8_{\text {Diff,max,NOx }}$ ), to see what the effect of added $\mathrm{NO}_{\mathrm{x}}$ emissions from shale gas was on MDA8 per grid cell and per day.

7. The top 30 highest MDA8 $8_{\text {Diff,max,NOx }}$ values for both Germany and the UK were recorded.

8. Of these top 30 values for each country, cells which formed a continuous area were filtered for. Note that in Germany a continuous area of about 4 grid cells was filtered for, and for the UK an area of about 5 grid cells, based on the size of the concentrated $\mathrm{NO}_{\mathrm{x}}$ activities and the resolution, i.e., size of each grid cell of the output grid.

9. Based on these steps, a rough area that may be especially sensitive to concentrated $\mathrm{NO}_{\mathrm{x}}$ emissions for increased MDA8 production was determined. Note that it was not possible to determine the exact area because of inherent and unavoidable differences between the output grid and preprocessing grid. That is to say, because the output grid and pre-processing grid contain differing horizontal resolutions, the grid cell lat/lon coordinates likewise differ.

10. After having determined a rough continuous area which displays a heightened sensitivity to added $\mathrm{NO}_{\mathrm{x}}$ emissions for increased MDA8 production in the output grid, the closest lat and lon coordinates of the pre-processing grid matching the coordinates of the output grid were determined.

11. After determining this, a new mask was created for the concentrated $\mathrm{NO}_{\mathrm{x}}$ area, for each country, adapted to the pre-processing grid. The mask was located roughly in the same area as the output grid.

12. Again, due to slight differences and discrepancies in coordinates as a result of converting from one grid to the other, the concentrated $\mathrm{NO}_{\mathrm{x}}$ mask was checked against the shale gas basin mask of each country to ensure that the $\mathrm{NO}_{\mathrm{x}}$ mask was roughly within the shale gas region; the mask was adjusted as necessary.

\section{Equation S1}

In order to provide statistical data (Table S2) on maximum difference in MDA8, the maximum of the difference in MDA8 between the scenario and base case at time $t$ is calculated for every $x y$ coordinate over region $R(\triangle \mathrm{MDA} 8)$.

$$
\Delta M D A 8(t)=\max \left(M D A 8_{\text {scenario }}(t, x, y)-M D A 8_{\text {Base }}(t, x, y)\right) \forall x y \in R
$$


Table S2. Summary of $\mathbf{\Delta M D A 8}$ statistical data over the whole domain in $\boldsymbol{\mu g} \mathbf{~ m}^{-\mathbf{3}}$, over JJA

$\begin{array}{lll}\text { SG1 SG2 } & \text { SG3 }\end{array}$

Statistical

\begin{tabular}{llllllllll} 
data & dry gas & wet gas & conNO $_{\mathrm{x}}$ & dry gas & wet gas & conNO $_{\mathrm{x}}$ & dry gas & wet gas & conNO $_{\mathrm{x}}$ \\
\hline Minimum & 0.3 & 0.4 & 0.4 & 0.3 & 0.6 & 0.8 & 0.6 & 1.8 & 1.6 \\
Q1 & 0.8 & 1.1 & 1.4 & 1.0 & 1.6 & 1.8 & 1.4 & 5.0 & 5.0 \\
Median & 1.2 & 1.4 & 2.1 & 1.3 & 2.5 & 2.9 & 2.1 & 6.7 & 6.3 \\
Q3 & 1.6 & 2.0 & 3.2 & 1.8 & 3.2 & 4.0 & 2.7 & 10.2 & 9.7 \\
Maximum & 3.7 & 4.5 & 9.5 & 3.9 & 6.5 & 9.6 & 4.8 & 28.3 & 23.3 \\
Average & 1.4 & 1.6 & 2.6 & 1.5 & 2.6 & 3.2 & 2.2 & 8.0 & 7.5
\end{tabular}

Table S3. Stations per country and exceedance data per country with respect to the EU threshold, over JJA

\begin{tabular}{|c|c|c|c|c|c|c|c|c|c|c|c|c|c|}
\hline \multirow{3}{*}{ Country } & \multicolumn{5}{|c|}{ SG1 } & \multicolumn{4}{|c|}{ SG2 } & \multicolumn{4}{|c|}{ SG3 } \\
\hline & & \multicolumn{2}{|c|}{ dry gas } & \multicolumn{2}{|c|}{ wet gas } & \multicolumn{2}{|c|}{ dry gas } & \multicolumn{2}{|c|}{ wet gas } & \multicolumn{2}{|c|}{ dry gas } & \multicolumn{2}{|c|}{ wet gas } \\
\hline & $\sum_{e}^{a}$ & $\Sigma_{e}^{b}$ & $\%^{\mathrm{c}}$ & $\Sigma$ & $\%$ & $\Sigma_{e}$ & $\%$ & $\Sigma_{\mathrm{e}}$ & $\%$ & $\Sigma_{\mathrm{e}}$ & $\%$ & $\Sigma$ & $\%$ \\
\hline France & 386 & 27 & 7 & 32 & 8 & 30 & 8 & 41 & 11 & 40 & 10 & 67 & 17 \\
\hline Italy & 244 & 17 & 7 & 20 & 8 & 18 & 7 & 23 & 9 & 21 & 9 & 37 & 15 \\
\hline Germany & 234 & 4 & 2 & 4 & 2 & 4 & 2 & 6 & 3 & 5 & 2 & 16 & 7 \\
\hline Spain & 129 & 1 & 1 & 2 & 2 & 1 & 1 & 3 & 2 & 3 & 2 & 5 & 4 \\
\hline Austria & 111 & 2 & 2 & 4 & 4 & 4 & 4 & 4 & 4 & 4 & 4 & 6 & 5 \\
\hline U. Kingdom & 80 & 1 & 1 & 3 & 4 & 3 & 4 & 5 & 6 & 5 & 6 & 15 & 19 \\
\hline Poland & 61 & 1 & 2 & 1 & 2 & 1 & 2 & 2 & 3 & 2 & 3 & 2 & 3 \\
\hline Czech Rep. & 60 & 0 & 0 & 0 & 0 & 0 & 0 & 2 & 3 & 2 & 3 & 5 & 8 \\
\hline Belgium & 42 & 0 & 0 & 0 & 0 & 0 & 0 & 2 & 5 & 2 & 5 & 5 & 12 \\
\hline Hungary & 17 & 0 & 0 & 1 & 6 & 0 & 0 & 1 & 6 & 1 & 6 & 2 & 12 \\
\hline Sweden & 12 & 0 & 0 & 0 & 0 & 0 & 0 & 0 & 0 & 0 & 0 & 0 & 0 \\
\hline Netherlands & 15 & 0 & 0 & 0 & 0 & 0 & 0 & 0 & 0 & 0 & 0 & 1 & 8 \\
\hline Slovakia & 11 & 0 & 0 & 0 & 0 & 0 & 0 & 0 & 0 & 0 & 0 & 1 & 9 \\
\hline Denmark & 7 & 1 & 14 & 1 & 14 & 1 & 14 & 1 & 14 & 1 & 14 & 2 & 29 \\
\hline Serbia & 6 & 1 & 17 & 1 & 17 & 1 & 17 & 1 & 17 & 1 & 17 & 1 & 17 \\
\hline
\end{tabular}

${ }^{a}$ Number of stations with valid measurements per country. Only country stations which are located within the model domain are included in the analysis. 
${ }^{\mathrm{b}}$ Number of stations that experience exceedances per country.

${ }^{c}$ Percentage of stations per country that have an exceedance.

\section{Wind rose: modelled values for JJA \\ SpdAve=4 SpdStd=2 DirAve=272 No Calm Reports Nwnd=49019808 \\ Frequency circles every $10 \%$. Mean speed indicated.}

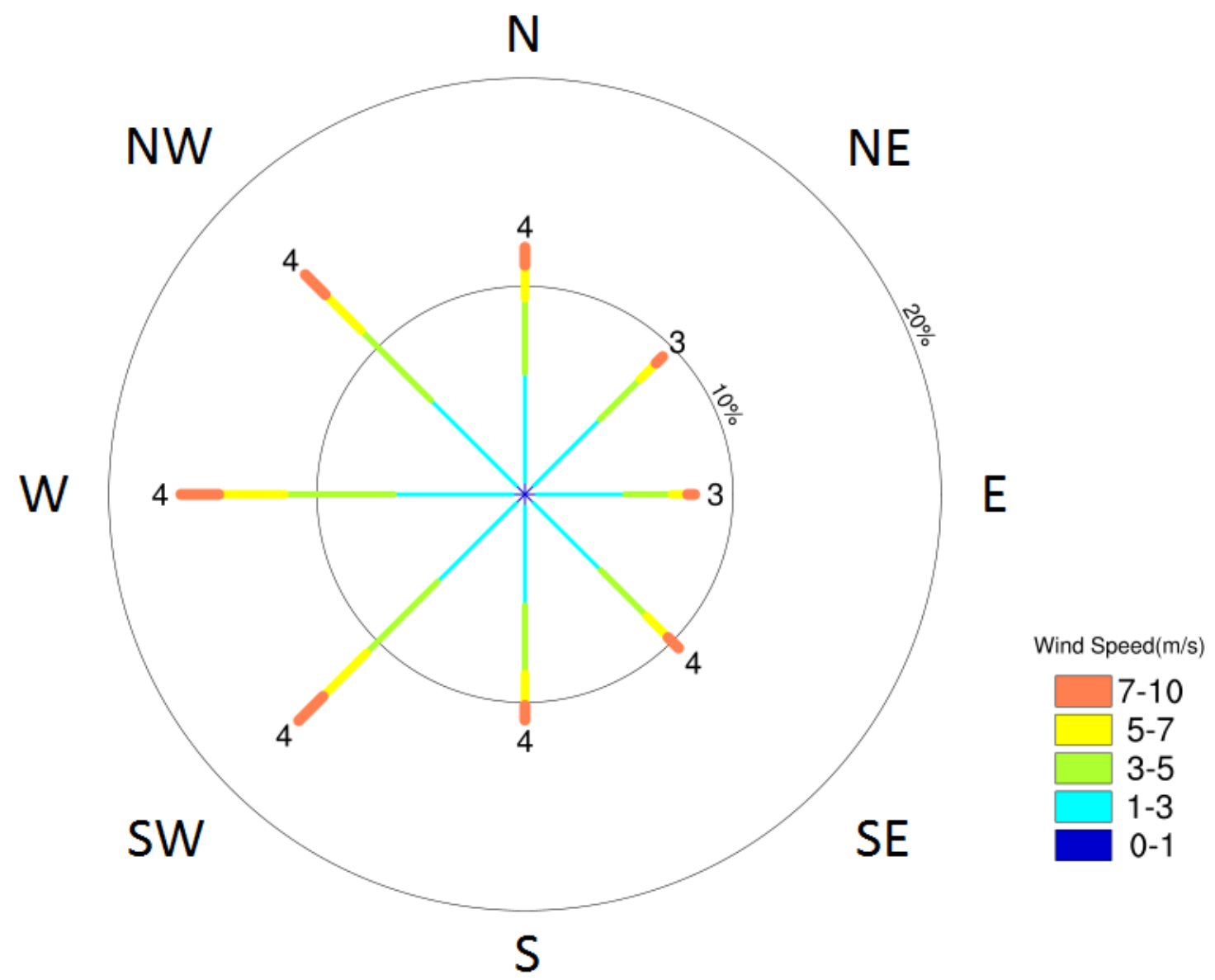

Figure S1. Wind rose diagram of hourly modeled values over domain for JJA. The length of each directional bar indicates the frequency (percentage of time) that wind blows from the respective direction, where each concentric circle represents a different frequency. The colors indicate the percentage of time that wind blows from a particular direction at a certain speed, in units of $\mathrm{m} \cdot \mathrm{s}^{-1}$. The number at the end of each directional bar indicates the average wind speed from that direction. Overall statistics for the entire data sample are included in the title, where SpdAve = wind speed average; SpdStd = standard deviation of the wind speed average; DirAve = directional average; Nwnd = number of modelled values. No calm reports means that there were no modeled data points where the wind speed was at exactly 0 . 

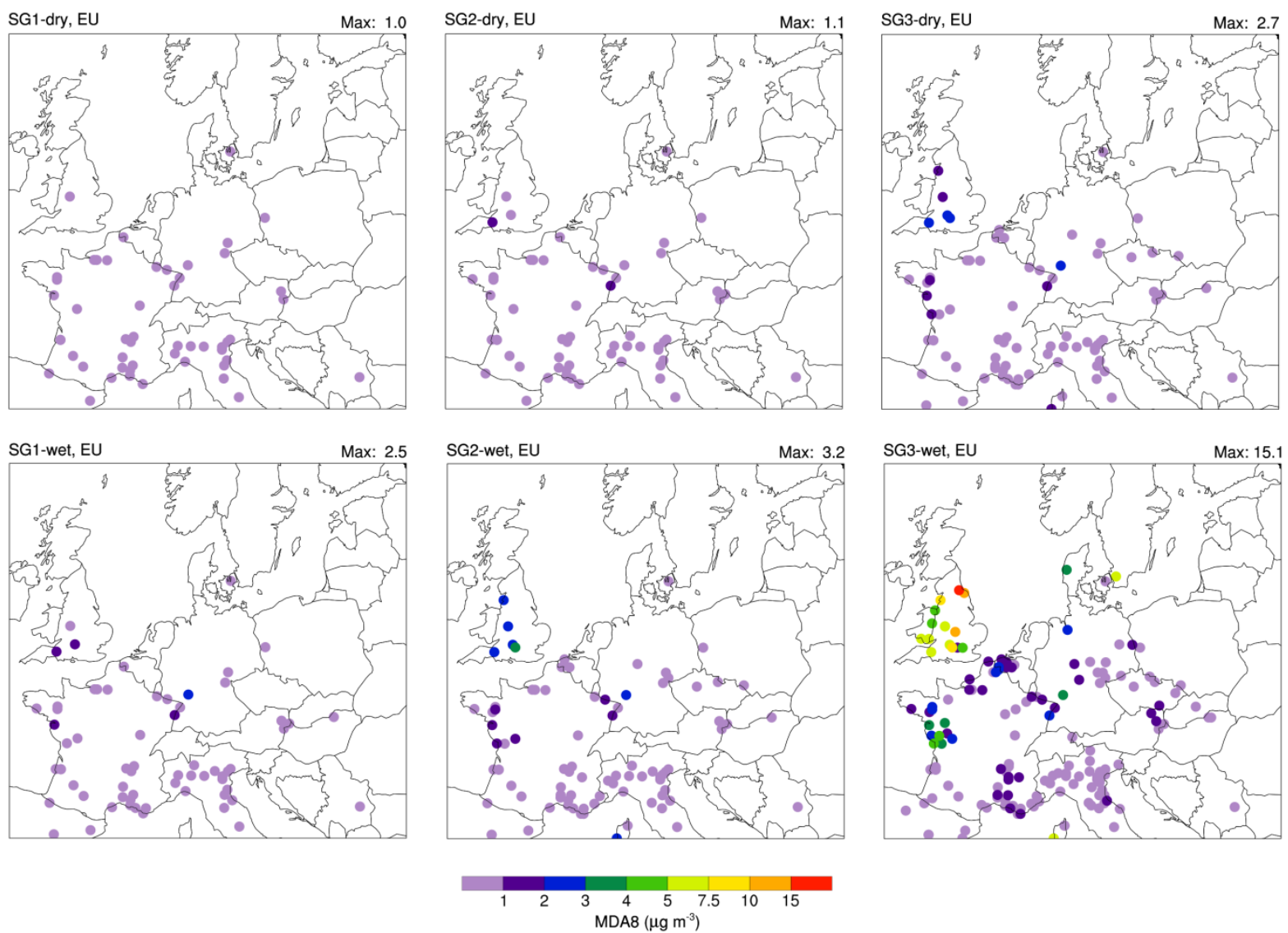

Figure S2. Spatial depiction of exceedances and corresponding exceedance magnitude. Exceedance

magnitude is defined as the difference between the shale gas scenarios and base case when an exceedance occurs, and is an indicator of the robustness of shale gas emissions on an exceedance. Exceedances are displayed as filled dots at the station locations where they occur, in $\mu \mathrm{g} \mathrm{m}^{-3}$, over JJA, applying the EU guideline for $\mathrm{O}_{3}$ as the threshold $\left(120 \mu \mathrm{g} \mathrm{m}^{-3}\right)$. For stations which experienced more than one exceedance, the maximum exceedance magnitude is shown. The top left-hand corner of each plot indicates the particular scenario, and the top right-hand corner displays the maximum exceedance magnitude value experienced over the domain and simulation period. 

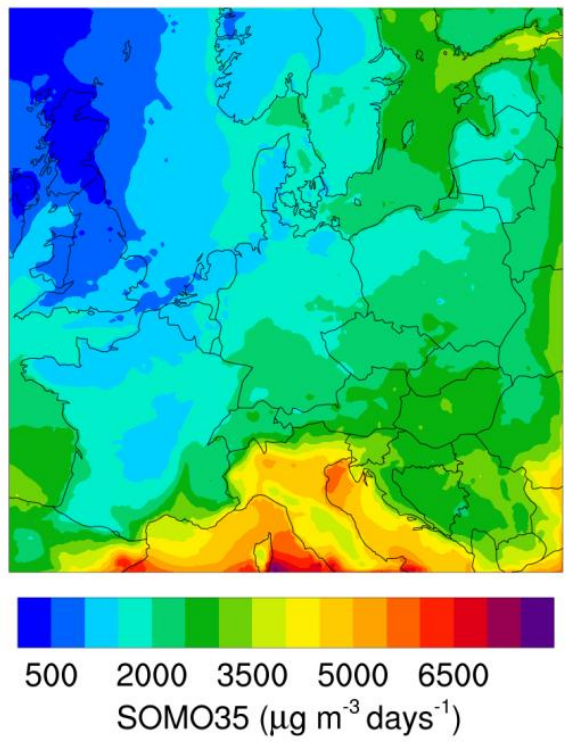

Figure S3. Surface plot of SOMO35 (annual Sum of Ozone Means Over 35 ppb, daily maximum 8hour) for base case simulation, in $\boldsymbol{\mu g} / \mathbf{m}^{3}$-days, over JJA. SOMO35 is an indicator of accumulated $\mathrm{O}_{3}$ exposure.

\section{References}

Cremonese L, Weger LB, Denier van der Gon HAC, Bartels M, Butler TM. 2019. Emission scenarios of a potential shale gas industry in Germany and the United Kingdom. Elem Sci Anth 7(1): 18. doi:10.1525/elementa.359. 